\title{
The Influence of Different Contents of Bi Addition on the Corrosion Behavior of Various Zirconium-Based Alloys
}

\author{
Meiyi Yao ${ }^{1,2^{*}}$, Xiaotong $\mathrm{Wu}^{1,2}$, Wenrong Duan ${ }^{1,2}$, Weipeng Zhang ${ }^{1,2}$, Li Zhu ${ }^{1,2}$, \\ Linghong Zou ${ }^{1,2}$, Jinlong Zhang ${ }^{1,2}$, Qiang Li ${ }^{1,2}$, Bangxin Zhou ${ }^{1,2}$ \\ ${ }^{1}$ Laboratory for Microstructures, Shanghai University, Shanghai, China \\ ${ }^{2}$ Institute of Materials, Shanghai University, Shanghai, China \\ Email: *yaomeiyi@shu.edu.cn
}

Received 12 January 2016; accepted 6 March 2016; published 10 March 2016

Copyright @ 2016 by authors and Scientific Research Publishing Inc.

This work is licensed under the Creative Commons Attribution International License (CC BY). http://creativecommons.org/licenses/by/4.0/

(c) (i) Open Access

\begin{abstract}
Zr-4(Zr-1.5Sn-0.2Fe-0.1Cr, wt\%), S5(Zr-0.8Sn-0.34Nb-0.39Fe-0.1Cr), T5(Zr-0.7Sn-1.07Nb-0.32Fe$0.08 \mathrm{Cr}$ ) and $\mathrm{Zr}-1 \mathrm{Nb}$ were adopted to prepare Bi-containing zirconium alloys for systematically investigating the effect of $B i$ addition on the corrosion resistance of zirconium alloys. The specimens were corroded in superheated steam at $400^{\circ} \mathrm{C} / 10.3 \mathrm{MPa}$, and in lithiated water with $0.01 \mathrm{M} \mathrm{LiOH}$ or in deionized water at $360^{\circ} \mathrm{C} / 18.6 \mathrm{MPa}$ by autoclave testing. Results show that the corrosion resistance increases with the increasing of Bi content dissolved in $\alpha$-Zr. But the presence of Bi-containing second phase particles (SPPs) is unfavorable for the enhancement of corrosion resistance. This indicates that the Bi dissolved in $\alpha$ - $\mathrm{Zr}$ matrix plays an important role in improving the corrosion resistance, while the precipitation of the Bi-containing SPPs does harm to the corrosion resistance.
\end{abstract}

\section{Keywords}

Bi, Zirconium Alloy, Corrosion Resistance, SPPs

\section{Introduction}

Zirconium-based alloys have been used as fuel cladding materials in pressurized water reactors due to their low cross-section for thermal neutron absorption, good corrosion resistance and adequate mechanical properties. However, the waterside corrosion resistance of the fuel cladding affects the service life of high burn-up fuel as-

${ }^{*}$ Corresponding author.

How to cite this paper: Yao, M.Y., Wu, X.T., Duan, W.R., Zhang, W.P., Zhu, L., Zou, L.H., Zhang, J.L., Li, Q. and Zhou, B.X. (2016) The Influence of Different Contents of Bi Addition on the Corrosion Behavior of Various Zirconium-Based Alloys. Journal of Environmental Protection, 7, 495-501. http://dx.doi.org/10.4236/jep.2016.74044 
semblies. The higher demand for burn-up and refueling period in reactor requires new zirconium alloys with advanced performances [1]-[4].

There are three series (Zr-Sn, Zr-Sn-Nb and Zr-Nb) of promising zirconium alloys, such as Zr-4 (Zr-1.5Sn0.2Fe-0.1Cr, wt\%) (Zr-Sn serie), S5 (Zr-0.8Sn-0.34Nb-0.39Fe-0.1Cr) (Zr-Sn-Nb serie), T5 (Zr-0.7Sn-1.07Nb$0.32 \mathrm{Fe}-0.08 \mathrm{Cr}$ ) (Zr-Sn-Nb serie) and $\mathrm{Zr}-1 \mathrm{Nb}$ (Zr-Nb serie). Optimizing composition of zirconium alloys is a common method to develop new alloys with excellent corrosion resistance [5] [6]. Many researches showed that the influence of alloying elements on the corrosion resistance depended on the concentration of alloying elements in $\alpha$-Zr matrix: the corrosion resistance of zirconium alloys was improved with the increase of the content of alloying elements ( $\mathrm{Cu}, \mathrm{Fe}, \mathrm{Cr}$ ) dissolved in $\alpha$-Zr [7]-[12]. It indicates that alloying elements with relative high concentration in $\alpha-\mathrm{Zr}$ are possible alloying elements of zirconium alloys from consideration of their solid solute content dissolved in $\alpha$-Zr. The solubility of many alloying elements are very low (the maximum solubility of $120 \mu \mathrm{g} / \mathrm{g}$ at $700^{\circ} \mathrm{C}$ for $\mathrm{Fe}$ and the maximum solubility of $0.1 \mathrm{wt} \%$ at $580^{\circ} \mathrm{C}$ for $\mathrm{Cu}$ ), while the solubility of $\mathrm{Bi}$ in $\alpha-\mathrm{Zr}$ is $6 \mathrm{wt} \%$ at $580^{\circ} \mathrm{C}$ according to $\mathrm{Zr}-\mathrm{Bi}$ phase graph [13]. $\mathrm{Bi}$ is also a suitable alloying element from consideration of capture cross-section for thermal neutrons. And it was reported that adding $0.1 \mathrm{wt} \%$ to $0.5 \mathrm{wt} \% \mathrm{Bi}$ can improve the corrosion resistance of Zr-1Nb alloy [14]. So far, there is no systematic research on Bi. From the consideration of the solubility and cross-section for thermal neutron absorption, our group studied the effect of $\mathrm{Bi}$ on the microstructures and corrosion resistance of various zirconium alloys. Zr-4, S5, T5 and Zr- $1 \mathrm{Nb}$ were adopted as matrix alloys to prepare the zirconium alloys containing Bi of $0.05 \mathrm{wt} \%-0.5 \mathrm{wt} \%$. The microstructure of these zirconium alloys and part of corrosion results have been reported in [15]-[19]. The corrosion resistance of these Bi-containing zirconium alloys was systematically reported to comprehensively understand the influence law of the different contents of Bi addition on the corrosion behavior of various zirconium-based alloys in this study.

\section{Materials and Experiments}

Four series of Bi-containing alloys were prepared by adding $0.05 \mathrm{wt} \%-0.5 \mathrm{wt} \% \mathrm{Bi}$ into $\mathrm{Zr}-4, \mathrm{~S} 5, \mathrm{~T} 5$ and $\mathrm{Zr}-$ $1 \mathrm{Nb}$ matrix alloys, denoted as $\mathrm{Zr}-4+x \mathrm{Bi}(x=0.1,0.3,0.5$, wt\% $), \mathrm{S} 5+x \mathrm{Bi}(x=0.1,0.3,0.5), \mathrm{T} 5+x \mathrm{Bi}(x=0.1$, $0.3,0.5)$ and $\mathrm{Zr}-1 \mathrm{Nb}+x \mathrm{Bi}(x=0.05,0.1,0.2,0.3)$, respectively. The composition and preparation procedures of experimental alloys have been reported in [19] in details. As an aid to the readers, the preparation procedures of experimental alloys are shown in Figure 1. Alloy ingots of about $65 \mathrm{~g}$ were smelted by vacuum non-consumable arc smelting. In order to homogenize the composition of alloys, each ingot was turned over and smelted for 6 times. The ingots were made into plates with about $0.7 \mathrm{~mm}$ in thickness after they underwent hot-pressing at $700^{\circ} \mathrm{C}$, homogenizing annealing at $1030^{\circ} \mathrm{C}$ for $40 \mathrm{~min}$, hot-rolling at $700^{\circ} \mathrm{C}, \beta$-quenching at $1030^{\circ} \mathrm{C}$ for $40 \mathrm{~min}$, cold-rolling and final annealing at $580^{\circ} \mathrm{C}$ for $5-50 \mathrm{~h}$. Last two steps were different for the four series of alloys. Procedure $\mathrm{A}$ is for $\mathrm{T} 5+x \mathrm{Bi}$, $\mathrm{S} 5+x \mathrm{Bi}$ and $\mathrm{Zr}-4+x \mathrm{Bi}$ alloys, and procedure $\mathrm{B}$ is for $\mathrm{Zr}-1 \mathrm{Nb}+x \mathrm{Bi}$ alloys.

The specimens were chemically polished using a mixed acid solution $\left(30 \mathrm{vol} \% \mathrm{H}_{2} \mathrm{O}+30 \mathrm{vol} \% \mathrm{HNO}_{3}+30\right.$ vol\% $\mathrm{H}_{2} \mathrm{SO}_{4}+10 \mathrm{vol} \% \mathrm{HF}$ ) before every annealing. The corrosion tests were conducted in superheated steam at

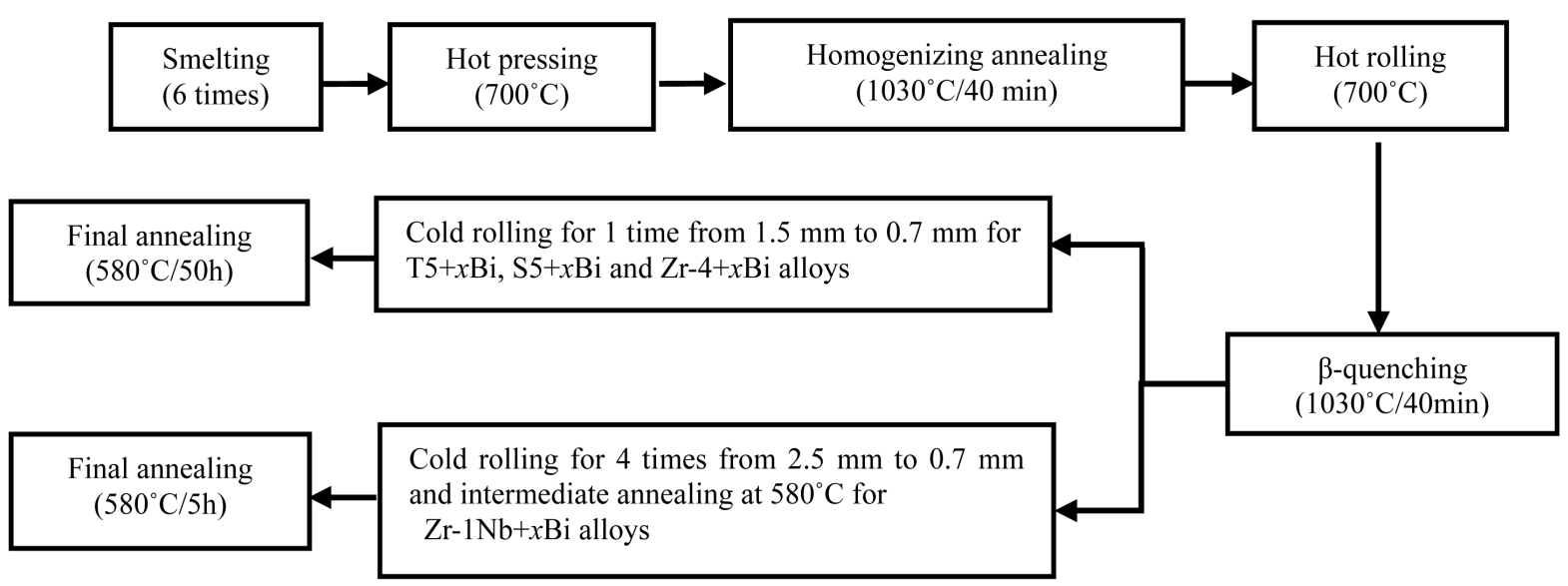

Figure 1. Preparation procedures of experimental alloys. 
$400^{\circ} \mathrm{C} / 10.3 \mathrm{MPa}$, and in lithiated water with $0.01 \mathrm{M} \mathrm{LiOH}$ or in deionized water at $360^{\circ} \mathrm{C} / 18.6 \mathrm{MPa}$ by static autoclave testing, according to ASTM G 2/G 2M-06. The corrosion resistance was evaluated by measuring the weight gain per unit surface area in relation to the exposure time. The reported weight gain was a mean value obtained from 3 - 5 specimens. Before the corrosion test, the specimens were cleaned and pickled in a mixed acid which has been mentioned above, sequentially rinsed in cold tap water, boiling deionized water and then blow-dried with warm air.

\section{Results and Discussion}

\subsection{Results}

The final corrosion weight gains of $\mathrm{Zr}-4+x \mathrm{Bi}$, $\mathrm{S} 5+x \mathrm{Bi}$ and $\mathrm{T} 5+x \mathrm{Bi}$ alloys vs. Bi content in lithiated water with $0.01 \mathrm{M} \mathrm{LiOH}$ at $360^{\circ} \mathrm{C} / 18.6 \mathrm{MPa}$ and in superheated steam at $400^{\circ} \mathrm{C} / 10.3 \mathrm{MPa}$ are shown in Figure 2. It can be seen that the addition of $0.1 \%-0.5 \% \mathrm{Bi}$ to $\mathrm{Zr}-4$ is harmful to the corrosion resistance and the variation of $\mathrm{Bi}$ contents has a remarkable effect on the corrosion resistance in both corrosion conditions; the corrosion resistance of the $\mathrm{Zr}-4+x \mathrm{Bi}$ alloy markedly decreased with the increase of $\mathrm{Bi}$ content, especially in superheated steam. The addition of $0.1 \%-0.5 \%$ Bi to S5 has a little beneficial effect on the corrosion resistance in lithiated water, and it can also improve the corrosion resistance in superheated steam, but the improvement effect decreases with the increasing $\mathrm{Bi}$ content. Adding $0.1 \%-0.5 \% \mathrm{Bi}$ to $\mathrm{T} 5$ can also improve the corrosion resistance in lithiated water, while in superheated steam, the addition of not more than $0.3 \% \mathrm{Bi}$ can enhance the corrosion resistance, but adding $0.5 \% \mathrm{Bi}$ is deleterious to the corrosion resistance. Other than the above alloys, $0.05 \%-0.3 \%$ $\mathrm{Bi}$ addition exhibits a beneficial effect on the corrosion resistance of $\mathrm{Zr}-1 \mathrm{Nb}$ alloy and the corrosion resistance is markedly improved with the increase of $\mathrm{Bi}$ content whether in deionized water at $360^{\circ} \mathrm{C} / 18.6 \mathrm{MPa}$ [15] or in superheated steam at $400^{\circ} \mathrm{C} / 10.3 \mathrm{MPa}$ (Figure 3) [20]. This illustrates that the effect of Bi addition on the corrosion behavior of various zirconium-based alloys depends on the original compositions of alloys and corrosion circumstances.

\subsection{Discussion}

Our group has reported the microstructure of the above Bi-containing zirconium alloys in detail in [15]-[19]. The results are descripted in brief as follows: the maximum Bi content dissolved in $\alpha$ - $\mathrm{Zr}$ matrix (denoted as $\mathrm{C}_{\mathrm{Bi} \text {,max }}$ ) was different for various zirconium-based alloys according to appearing Bi-containing SPPs: less than $0.1 \%$ for the $\mathrm{Zr}-4+x \mathrm{Bi}$ alloys, $0.1 \%$ to $0.3 \%$ for the $\mathrm{S} 5+x \mathrm{Bi}$ alloys, $0.3 \%$ to $0.5 \%$ for the $\mathrm{T} 5+x \mathrm{Bi}$ alloys, and more than $0.3 \%$ for the $\mathrm{Zr}-1 \mathrm{Nb}+x \mathrm{Bi}$ alloys (The data in Table 1 are taken from our previous study [19]). According to the $\mathrm{Zr}-\mathrm{Bi}$ binary phase diagram, the Bi solubility in $\alpha$-Zr is about $6 \mathrm{wt} \%$ at $580^{\circ} \mathrm{C}$ [13]. Therefore, there should not

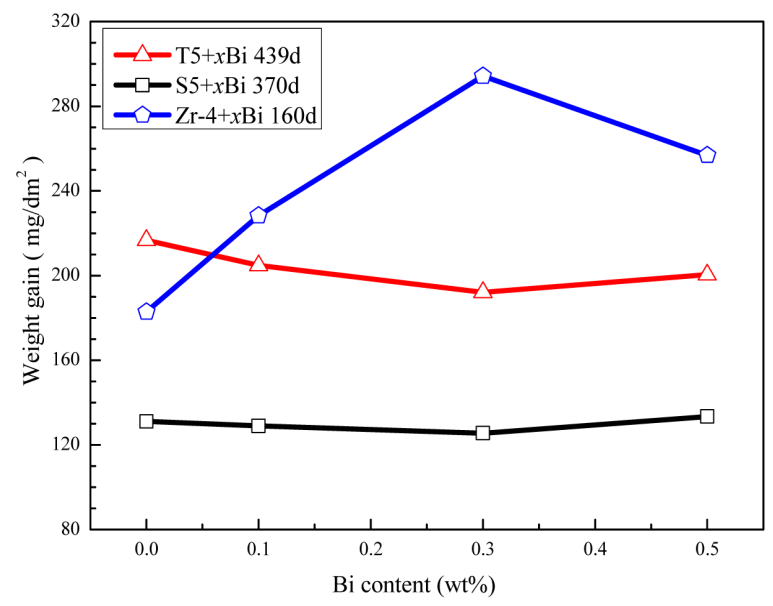

(a)

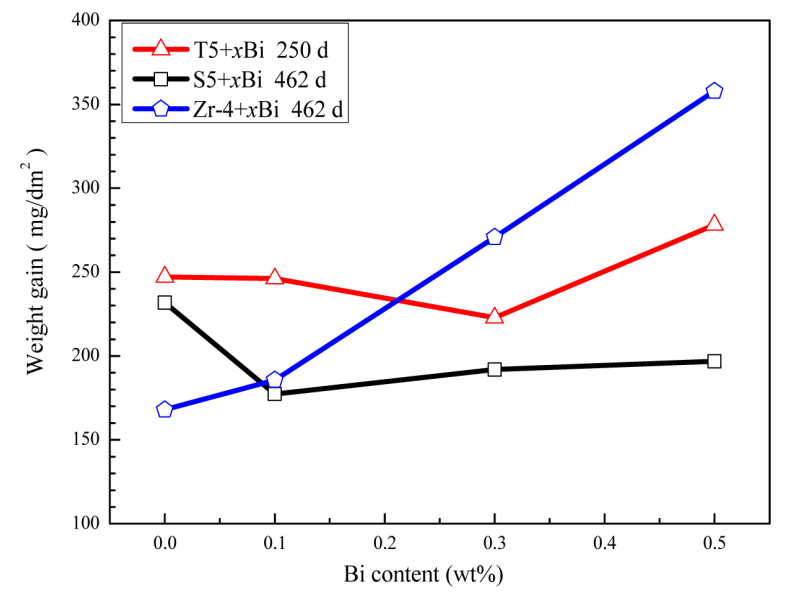

(b)

Figure 2. Final corrosion weight gains of $\mathrm{Zr}-4+x \mathrm{Bi}$, $\mathrm{S} 5+x \mathrm{Bi}$ and $\mathrm{T} 5+x \mathrm{Bi}$ alloys vs. Bi content in lithiated water at $360^{\circ} \mathrm{C} /$ 18.6 $\mathrm{MPa}(\mathrm{a})$ and in superheated steam at $400^{\circ} \mathrm{C} / 10.3 \mathrm{MPa}$ (b). 


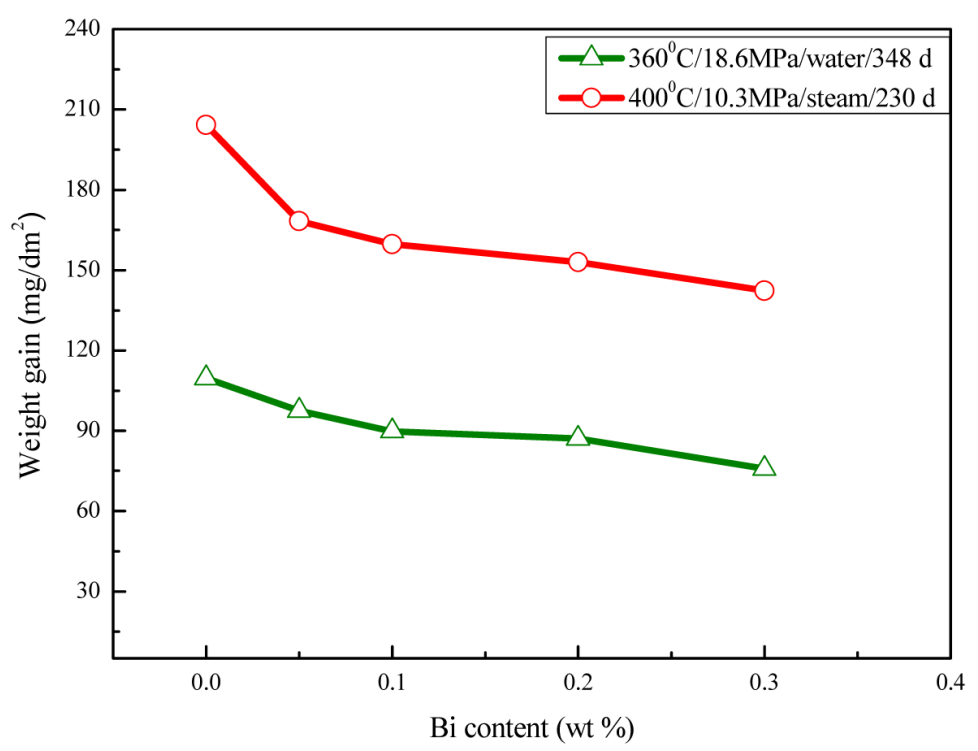

Figure 3. Final corrosion weight gains of $\mathrm{Zr}-1 \mathrm{Nb}+x \mathrm{Bi}$ alloys vs. Bi content in deionized water at $360^{\circ} \mathrm{C} / 18.6 \mathrm{MPa}$ and in superheated steam at $400^{\circ} \mathrm{C} / 10.3 \mathrm{MPa}[20]$.

Table 1. The information of SPPs in the alloys [19].

\begin{tabular}{|c|c|c|c|c|}
\hline \multirow{2}{*}{ Alloy } & \multicolumn{4}{|c|}{ Information of SPPs } \\
\hline & Remelted & $0.1 \mathrm{Bi}$ & $0.3 \mathrm{Bi}$ & $0.5 \mathrm{Bi}$ \\
\hline \multirow{4}{*}{$\begin{array}{l}\mathrm{Zr}-4+x \mathrm{Bi} \\
(\mathrm{Sn}: 1.5 \%)\end{array}$} & \multirow{4}{*}{$\mathrm{h}-\mathrm{Zr}(\mathrm{Fe}, \mathrm{Cr})_{2}$} & h-Zr(Fe,Cr $)_{2}$ & $\mathrm{~h}-\mathrm{Zr}(\mathrm{Fe}, \mathrm{Cr})_{2}$ & Zr-Fe-Sn-Bi \\
\hline & & \multirow{3}{*}{ Zr-Fe-Sn-Bi } & \multirow{3}{*}{ Zr-Fe-Cr-Sn-Bi } & Zr-Fe-Cr-Sn-Bi \\
\hline & & & & \\
\hline & & & & $\mathrm{Zr}-\mathrm{Fe}-\mathrm{Cr}-\mathrm{Bi}$ \\
\hline \multirow{3}{*}{$\begin{array}{c}\mathrm{S} 5+x \mathrm{Bi} \\
\text { (Sn: 0.8\%) }\end{array}$} & \multirow{3}{*}{$\mathrm{Zr}(\mathrm{Fe}, \mathrm{Cr}, \mathrm{Nb})_{2}$} & \multirow{3}{*}{$\mathrm{h}-\mathrm{Zr}(\mathrm{Fe}, \mathrm{Cr}, \mathrm{Nb})_{2}$} & h-Zr(Fe,Cr,Nb $)_{2}$ & $\mathrm{~h}-\mathrm{Zr}(\mathrm{Fe}, \mathrm{Cr}, \mathrm{Nb})_{2}$ \\
\hline & & & \multirow{2}{*}{$\mathrm{o}-\mathrm{Zr}(\mathrm{Bi}, \mathrm{Sn}, \mathrm{Fe})_{2}$} & $\mathrm{o}-\mathrm{Zr}(\mathrm{Bi}, \mathrm{Sn}, \mathrm{Fe})_{2}$ \\
\hline & & & & Zr-Fe-Cr-Nb-Sn-Bi \\
\hline \multirow{3}{*}{$\begin{array}{c}\mathrm{T} 5+x \mathrm{Bi} \\
(\mathrm{Sn}: 0.7 \%)\end{array}$} & \multirow{3}{*}{ h-Zr(Fe,Cr,Nb $)_{2}$} & \multirow{3}{*}{ h-Zr(Fe,Cr,Nb $)_{2}$} & \multirow{3}{*}{$\mathrm{h}-\mathrm{Zr}(\mathrm{Fe}, \mathrm{Cr}, \mathrm{Nb})_{2}$} & $\mathrm{~h}-\mathrm{Zr}(\mathrm{Fe}, \mathrm{Cr}, \mathrm{Nb})_{2}$ \\
\hline & & & & $\mathrm{o}-\mathrm{Zr}(\mathrm{Fe}, \mathrm{Sn}, \mathrm{Bi})_{2}$ \\
\hline & & & & Zr-Fe-Cr-Nb-Sn-Bi \\
\hline $\begin{array}{c}\mathrm{Zr}-1 \mathrm{Nb}+x \mathrm{Bi} \\
\quad(\mathrm{Sn}: 0 \%)\end{array}$ & \multicolumn{4}{|c|}{$x \leq 0.3 \%$, none of Bi-containing SPPs was detected, and there were only $\beta$-Nb and $\mathrm{h}-\mathrm{Zr}(\mathrm{Nb}, \mathrm{Fe}, \mathrm{Cr})_{2}$} \\
\hline
\end{tabular}

be Bi-containing SPPs in the alloys with Bi content not more than $1 \%$. However, the Bi-containing SPPs were really detected in the experimental alloys in the Bi-containing zirconium alloys in this study. Moreover, the addition of $\mathrm{Bi}$ promotes the precipitation of Sn as SPPs. The content of Bi dissolved in $\alpha$-Zr matrix increases with the decrease of Sn content in the alloys. The reason has been discussed in [16] [19] in detail.

The effect of $\mathrm{Bi}$ addition on the corrosion behavior of various zirconium-based alloys is related to the original compositions of alloys and corrosion conditions. The optimizing content of $\mathrm{Bi}$ corresponding to the corrosion resistance is less than $0.1 \%$ for $\mathrm{Zr}-4,0.1 \%$ to $0.3 \%$ for $\mathrm{S} 5,0.3 \%$ for $\mathrm{T} 5$ and $0.3 \%$ for $\mathrm{Zr}-1 \mathrm{Nb}$ alloy based on this study, and the content of $\mathrm{Bi}$ is $0.1 \%$ for $\mathrm{Zr}-4,0.3 \%$ for $\mathrm{S} 5$ and $0.5 \%$ for $\mathrm{T} 5$ when the Bi-containing SPPs are 
precipitated. It indicates that the Bi dissolved in $\alpha$-Zr matrix is beneficial for improving the corrosion resistance of zirconium alloys, and the precipitation of the Bi-containing SPPs is harmful to the corrosion resistance.

When zirconium alloys are oxidized, the SPPs and the alloying elements dissolved in $\alpha$-Zr will also be oxidized, which affects the characteristics of oxide film, and ultimately influences the corrosion resistance of alloys. The oxidation of alloying elements dissolved in $\alpha-\mathrm{Zr}$ on the corrosion resistance of alloys has dispersive effect than that of SPPs; Moreover, Bi dissolved in $\alpha-\mathrm{Zr}$ can be more likely to dissolve in $\mathrm{ZrO}_{2}$ than the $\mathrm{Bi}$ in SPPs, which can reduce the decrease of surface free energy due to the infiltration of oxygen ions and hydroxide ions. Therefore, the vacancy in the oxide film cannot easily diffuse and condense to form the pore-clusters and cracks, and the corrosion resistance of zirconium alloys can be improved [21].

The addition of Bi lets Sn precipitate from $\alpha$-Zr matrix as SPPs. As the Piling-Bedworth of $\mathrm{Zr}$, Bi and Sn are 1.56, 2.27 and 1.32 [22], respectively, there will be major additional stresses when the SPPs are oxidized, which can promote the formation of pores and micro-cracks and provide more diffusion paths for oxygen ions and hydroxide ions, and eventually accelerate the corrosion of alloys. At the same time, the precipitation of SPPs containing Bi and Sn can counteract the improving effect of Bi dissolved in $\alpha-\mathrm{Zr}$ on the corrosion resistance of zirconium alloys. In addition, the precipitation of SPPs containing Bi and Sn also decreases the content of Sn dissolved in $\alpha$-Zr. It has been reported that Sn can offset the harmful effect of nitrogen in zirconium alloys, and too high or too low Sn content would produce disadvantageous effect on the corrosion resistance of zirconium alloys [22]. This may be the reason that the precipitation of SPPs containing Bi and $\mathrm{Sn}$ is harmful to improve the corrosion resistance of zirconium alloys.

From another angle, the corrosion of zirconium alloys in deionized water or in superheated steam with high temperature and pressure is also an electrochemical process. The SPPs at the $\mathrm{Zr} / \mathrm{ZrO}_{2}$ interface and $\alpha$ - $\mathrm{Zr}$ matrix constitute many micro batteries during oxidation, and $\alpha$-Zr matrix is preferentially oxidized as anode [23]. On one hand, the Bi dissolved in $\alpha$-Zr matrix may change the potential of matrix, and reduce the potential difference between the matrix and SPPs, which will slow down the process of electrochemical corrosion and improve the corrosion resistance of alloys; On the other hand, the addition of Bi change the composition and type of SPPs, and the potentials of various SPPs exist diffidence. Therefore, the electrochemical behavior of the system will be changed and the corrosion resistance of zirconium alloys will be affected.

Many researches thought that the concentrations of alloying elements dissolved in $\alpha$-Zr matrix were the main factor to affect the corrosion resistance of zirconium alloys [9]-[12] [24] [25]. Other researches considered the SPPs to be the main factor [4] [26] [27]. In this study, it is obvious that the Bi dissolved in $\alpha$ - Zr matrix plays a beneficial role in the corrosion resistance, while the Bi-containing SPPs precipitated from the matrix plays a harmful role in the corrosion resistance. This further illustrates that a suitable increase in concentration of alloying elements in $\alpha$ - $\mathrm{Zr}$ matrix is of benefit to improving the corrosion resistance of zirconium alloys [9]-[12] [24].

\section{Conclusion}

The effect of Bi addition on the corrosion behavior of various zirconium-based alloys depends on the compositions of mother alloys and corrosion conditions. The solid solution of $\mathrm{Bi}$ in $\alpha$-Zr matrix plays a beneficial role in the corrosion resistance of zirconium alloys, while the precipitation of the Bi-containing SPPs plays a harmful role in the corrosion resistance of zirconium alloys.

\section{Acknowledgements}

This study is partly supported by National Natural Science Foundation of China (Nos. 50971084 and 51271104) and National Advanced Pressurized Water Reactor Project of China (No. 2011ZX06004-023).

\section{References}

[1] Sabol, G.P., Kilp, G.R., Balfour, M.G. and Roberts, E. (1989) Development of a Cladding Alloy for Higher Burnup. Zirconium in the Nuclear Industry: 8th International Symposium, ASTM STP1023, ASTM, Philadelphia, 227-244.

[2] Nikulina, A.V., Markelov, V.A., Peregud, M.M., Bibilashvili, Y.K., Kotrekhov, V.A., Lositsky, A.F., et al. (1996) Zirconium Alloy E635 as a Material for Fuel Rod Cladding and Other Components of VVER and RBMK Cores. Zirconium in the Nuclear Industry: 11th International Symposium, ASTM STP1295, ASTM, Philadelphia, 785-804. http://dx.doi.org/10.1520/stp16201s

[3] Mardon, J.P., Charquet, D. and Senevat, J. (2000) Influence of Composition and Fabrication Process on Out-of-Pile 
and In-Pile Properties of M5 Alloy. Zirconium in the Nuclear Industry: 12th International Symposium, ASTM STP1354, ASTM, Philadelphia, 505-524. http://dx.doi.org/10.1520/stp14314s

[4] Comstock, R.J., Schoenberger, G. and Sabol, G.P. (1996) Influence of Processing Variables and Alloy Chemistry on the Corrosion Behavior of ZIRLO Nuclear Fuel Cladding. Zirconium in the Nuclear Industry: 11th International Symposium, ASTM STP1295, ASTM, Philadelphia, 710-725. http://dx.doi.org/10.1520/stp16198s

[5] Zhou, B.X., Yao, M.Y., Li, Z.K., Wang, X.M., Zhou, J., Long, C.S., et al. (2012) Optimization of N18 Zirconium Alloy for Fuel Cladding of Water Reactors. Journal of Material Science \& Technology, 28, 606-613. http://dx.doi.org/10.1016/S1005-0302(12)60105-4

[6] Yueh, H.K., Kesterson, R.L., Comstock, R.J., Shah, H.H., Colburn, D.J., Dahlback, M. and Hallstadius, L. (2005) Improved ZIRLO ${ }^{\mathrm{TM}}$ Cladding Performance through Chemistry and Process Modifications. Zirconium in the Nuclear Industry: 14th International Symposium, ASTM STP1467, ASTM, Philadelphia, 330-346. http://dx.doi.org/10.1520/jai12344

[7] Hong, H.S., Moon, J.S., Kim, S.J. and Lee, K.S. (2001) Investigation on the Oxidation Characteristics of CopperAdded Modified Zircaloy-4 Alloys in Pressurized Water at 360 ${ }^{\circ}$ C. Journal of Nuclear Materials, 297, 113-119. http://dx.doi.org/10.1016/S0022-3115(01)00601-8

[8] Park, J.Y., Choi, B.K., Yoo, S.J. and Jeong, Y.H. (2006) Corrosion Behavior and Oxide Properties of Zr-1.1 wt\%Nb0.05 wt\%Cu Alloy. Journal of Nuclear Materials, 359, 59-68. http://dx.doi.org/10.1016/j.jnucmat.2006.07.017

[9] Yao, M.Y., Zhang, Y., Li, S.L., Zhang, X., Zhou, J. and Zhou, B.X. (2011) Effect of Cu Content on the Corrosion Resistance of $\mathrm{Zr}-0.80 \mathrm{Sn}-0.34 \mathrm{Nb}-0.39 \mathrm{Fe}-0.10 \mathrm{Cr}-x \mathrm{Cu}$ Alloy in Superheated Steam at $500^{\circ} \mathrm{C}$. Acta Metallurgica Sinica, 47, 872-876. (In Chinese)

[10] Li, S.L., Yao, M.Y., Zhang, X., Geng, J.Q., Peng, J.C. and Zhou, B.X. (2011) Effect of adding Cu on the Corrosion Resistance of M5 Alloy in Superheated Steam at 500 ${ }^{\circ}$ C. Acta Metallurgica Sinica, 47, 163-168. (In Chinese)

[11] Yao, M.Y., Zhou, B.X., Li, Q., Liu, W.Q., Geng, X. and Lu, Y.P. (2008) A Superior Corrosion Behavior of Zircaloy-4 in Lithiated Water at $360^{\circ} \mathrm{C} / 18.6 \mathrm{MPa}$ by $\beta$-Quenching. Journal of Nuclear Materials, 374, 197-203. http://dx.doi.org/10.1016/j.jnucmat.2007.08.002

[12] Yao, M.Y., Shen, Y.F., Li, Q., Peng, J.C., Zhou, B.X. and Zhang, J.L. (2013) The Effect of Final Annealing after $\beta$ Quenching on the Corrosion Resistance of Zircaloy-4 in Lithiated Water with $0.04 \mathrm{M} \mathrm{LiOH}$. Journal of Nuclear Materials, 435, 63-70. http://dx.doi.org/10.1016/j.jnucmat.2012.12.029

[13] Okamoto, H. (1990) Zirconium-Bismuth System. Bulletin of Alloy Phase Diagrams, 11, 295-297.

[14] Li, P.Z., Li, Z.K., Xue, X.Y. and Liu, J.Z. (1998) Influence of Alloying Elements on the Corrosion Resistance of Zr-Nb Alloys. Rare Metal Material Engineering, 27, 356-359. (In Chinese)

[15] Zhu, L., Yao, M.Y., Sun, G.C., Chen, W.J., Zhang, J.L. and Zhou, B.X. (2013) Effect of Bi Addition on the Corrosion Resistance of Zr-1Nb Alloy in Deionized Water at $360^{\circ} \mathrm{C}$ and 18.6 MPa. Acta Metallurgica Sinica, 49, 51-57. (In Chinese)

[16] Chen, C.M., Yao, M.Y., Zhou, J., Zhou, B.X., Zhang, J.L., Li, Q., et al. (2015) The Corrosion Behavior of Zr-0.7Sn$1.07 \mathrm{Nb}-0.32 \mathrm{Fe}-0.08 \mathrm{Cr}-x \mathrm{Bi}$ Alloy in Superheated Steam at $400^{\circ} \mathrm{C} / 10.3 \mathrm{MPa}$. Rare Metal Material Engineering, 44, 933-938. (In Chinese)

[17] Yao, M.Y., Zou, L.H., Xie, X.F., Zhang, J.L., Peng, J.C. and Zhou, B.X. (2012) Effect of Bi Addition on the Corrosion Resistance of Zr-4 in Superheated Steam at $400^{\circ} \mathrm{C} / 10.3 \mathrm{MPa}$. Acta Metallurgica Sinica, 48, 1097-1102. (In Chinese)

[18] Zhang, W.P., Yao, M.Y., Zhu, L., Zhang, J.L., Zhou, B.X. and Li, Q. (2013) The Corrosion Behavior of Zr-0.8Sn$0.35 \mathrm{Nb}-0.4 \mathrm{Fe}-0.1 \mathrm{Cr}-x \mathrm{Bi}$ Alloy in Superheated Steam at $400^{\circ} \mathrm{C} / 10.3 \mathrm{MPa}$. Corrosion \& Protection, 34, 463-467. (In Chinese)

[19] Zhao, H.P., Yao M.Y., Huang, J., Zhang J.L., Peng, J.C. and Zhou B.X. (2016) The Microstructure of Bi-Containing Zirconium Alloys. Rare Metals, 1-8. http://dx.doi.org/10.1007/s12598-015-0677-0

[20] Yao, M.Y., Wu, X.T., Huang, J., Zhang, J.L., Zhang, X. and Zhou, B.X. (2015) Study on the Corrosion Resistance of Zr-1Nb-xM (M=S, Cu, Ge, Bi) Alloys. Oxidation of Metals, 84, 647-659. http://dx.doi.org/10.1007/s11085-015-9594-8

[21] Zhou, B.X., Li, Q., Yao, M.Y., Liu, W.Q. and Chu, Y.L. (2008) Effect of Water Chemistry and Composition on Microstructural Evolution of Oxide Film on Zr Alloy. In: Bruce, K. and Magnus, L., Eds., Zirconium in the Nuclear Industry: 15th International Symposium, ASTM STP1505, ASTM, Philadelphia, 360-383.

[22] Yang, W.D. (2006) Reactor Materials Science. 2nd Edition, Atomic Energy Press, Beijing. (In Chinese)

[23] Weidinger, H.G., Ruhmann, H., Cheliotis, G., Maguire, M. and Yau, T.L. (1991) Corrosion-Electrochemical Properties of Zirconium Intermetallics. In: Eucken, C.M. and Garde, A.M., Eds., Zirconium in the Nuclear Industry: Ninth International Symposium, ASTM STP 1132, ASTM, Philadelphia, 499-535. http://dx.doi.org/10.1520/stp25525s

[24] Jeong, Y.H., Lee, K.O. and Kim, H.G. (2002) Correlation between Microstructure and Corrosion Behavior of Zr-Nb 
Binary Alloy. Journal of Nuclear Materials, 302, 9-19. http://dx.doi.org/10.1016/S0022-3115(02)00703-1

[25] Jeong, Y.H., Kim, H.G., Kim, D.J., Choi, B.K. and Kim, J.H. (2003) Influence of Nb Concentration in the $\alpha$-Matrix on the Corrosion Behavior Zr- $x$ Nb Binary Alloys. Journal of Nuclear Materials, 323, 72-80. http://dx.doi.org/10.1016/j.jnucmat.2003.08.031

[26] Rudling, P. and Wikmark, G. (1999) A Unified Model of Zircaloy BWR Corrosion and Hydriding Mechanisms. Journal of Nuclear Materials, 265, 44-59. http://dx.doi.org/10.1016/S0022-3115(98)00613-8

[27] Rudling, P., Wikmark, G., Lehtinen, B. and Pettersson, H. (2000) Impact of Second Phase Particles on BWR Zr-2 Corrosion and Hydriding Performance. In: Sabol, G.P. and Moan, G.D., Eds., Zirconium in the Nuclear Industry: 12th International Symposium, ASTM STP 1354, ASTM, Philadelphia, 678-708. http://dx.doi.org/10.1520/stp14323s 